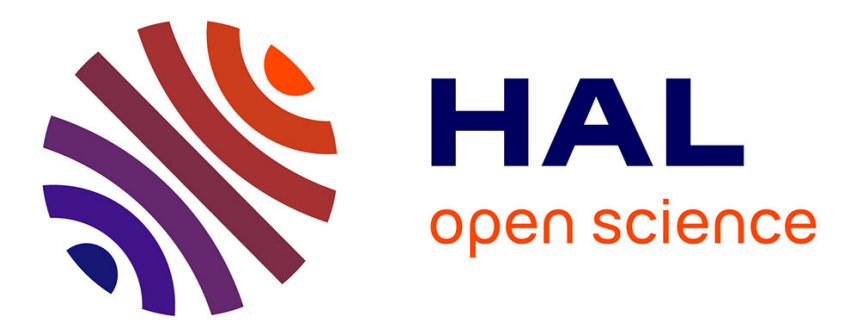

\title{
T-stress based short crack growth model for fretting fatigue
}

J. Bellecave, J.A. Araújo, S. Pommier, Y. Nadot, J. Meriaux

\section{To cite this version:}

J. Bellecave, J.A. Araújo, S. Pommier, Y. Nadot, J. Meriaux. T-stress based short crack growth model for fretting fatigue. Tribology International, 2014, 76, pp.23 - 34. 10.1016/j.triboint.2014.02.016 . hal-01636534

\section{HAL Id: hal-01636534 https://hal.science/hal-01636534}

Submitted on 17 Dec 2020

HAL is a multi-disciplinary open access archive for the deposit and dissemination of scientific research documents, whether they are published or not. The documents may come from teaching and research institutions in France or abroad, or from public or private research centers.
L'archive ouverte pluridisciplinaire HAL, est destinée au dépôt et à la diffusion de documents scientifiques de niveau recherche, publiés ou non, émanant des établissements d'enseignement et de recherche français ou étrangers, des laboratoires publics ou privés. 


\begin{abstract}
The aim of this work is to model short crack growth under fretting fatigue loading conditions by considering a criterion based on linear elastic fracture mechanics quantities, but which also accounts for the first non-singular terms of the asymptotic expansion, namely the T-stresses. The Modes I and II Stress Intensity Factors and the T-stresses were computed by the Finite Element Method under plane strain hypothesis. To assess the model fretting fatigue tests were carried out using two cylindrical fretting pads, which were loaded against a flat dogbone tensile test piece, both made of a Ti-6Al-4V titanium alloy. The model was capable to correctly estimate short crack arrest and to find the threshold fretting conditions separating failure from infinite life (here defined by tests which reached one million cycles). An optimization technique was implemented to the numerical model so that it could also estimate crack path.
\end{abstract}

Keywords: fretting-fatigue, T-stress, short crack, multiaxial, Ti-6Al-4V

\title{
1. Introduction
}

Fretting-fatigue appears when mechanical assemblies experience relative motion at contact interfaces under the action of an excitation force or vibration. Experimental evidence has shown that the conjoint action of fretting and fatigue may produce strength reduction factors varying from 2 up to $10[1]$.

Fretting failure of components such as splines and the dovetail fixing between blade and disc in fans of aeroengines [2] and riveted skins of the aircraft fuselage [3] have become a major design concern.

The aim of this work is to evaluate a $T$-stress based criterion [4][5] to model short crack growth under fretting fatigue conditions. The loads involved in fretting fatigue generate a time varying non-proportional multiaxial stress field under the contact [6], which decays very fast from the surface to the interior of the component [7]. Therefore, non-local approaches, developed initially for predicting the fatigue endurance of notched specimens, have been applied by different authors to the fretting fatigue problem $[6,8-10]$. Here, to model short crack growth under such challenge loading conditions we consider a criterion based on linear elastic fracture mechanics quantities

\footnotetext{
${ }^{*}$ Corresponding author

Email address: jbellecave@gmail.com (J. Bellecave)
} 
[11] and that accounts for the first non-singular terms of the asymptotic expansion, namely the $T$-stress.

The criterion is constructed as a generalized von Mises yield criterion and states that below the threshold value (a critical distortional elastic energy for the crack tip region) the crack should remain arrested. An elastic domain is thus defined which is function of the SIF and the Tstress. Within such model the mode I threshold stress intensity factor is not constant. It tends asymptotically towards the long crack threshold for long cracks and to zero for short cracks. The threshold value is also function of the stress biaxiality ratio, which is consistent with experiments from McEvily et al. [12].

The method was applied to the problem of fretting fatigue and shows that the high values of the $T$-stress encountered in this problem contribute to crack tip plasticity of short crack and may promote short crack growth. Fretting fatigue tests on Ti-6Al-4V have been carried out to evaluate the accuracy of the proposed methodology.

\section{Experimental results}

\subsection{Fretting fatigue apparatus and specimen}

Fretting fatigue tests were carried out using two cylindrical fretting pads, which were loaded against a flat dogbone tensile test piece. The pads used in the experimental and numerical work have a radius of $20 \mathrm{~mm}$, and a cross section of $13 \mathrm{~mm} \times 15 \mathrm{~mm}$, being $13 \mathrm{~mm}$ the out of plane thickness. The tests were performed for a Ti-6Al-4V titanium alloy. Specimens and pads were supplied and manufactured by Snecma from a fan disc of an aeroengine. Table 1 contains a list of static and fatigue material properties for this alloy, which are relevant for the analysis in this work, viz. Young's Modulus, E, Poisson's ratio, $\nu$, fully reversed fatigue limits under push-pull and torsion, $\sigma_{f_{R=-1}}$ and $\tau_{f_{R=-1}}$. These data were collected from the literature [13]. For the threshold value of the mode I SIF, $\Delta K_{t h_{R=-1}}$, data were found to vary between from $4.5 M P a . m^{1 / 2}$ [9] to $6.5 \mathrm{MPa} . \mathrm{m}^{1 / 2}$ [14]. Therefore, a mean value in this range was adopted for this study.

Before testing, pads and specimen were chemically degreased and, to assure the alignment of the contact between the cylindrical pads and the flat specimen was correct across the width of the specimen, a Pressure Measuring Film (Fuji Prescale Film - Medium Pressure - Mono Sheet Type) was selected. Fig.1 depicts a photograph of a pair of pads together with impressions made on the pressure sensitive paper after a correct alignment was performed.

Tests were carried out using a fretting apparatus which can be considered as an enhanced version of a device initially proposed by Nowell [15]. This apparatus is well detailed by Martins et al. [16] and only an overview of it is provided here. The apparatus is attached to a servo-hydraulic fatigue test frame and works as a spring that reacts to the motion of the pads, which are pressed by a static force against the dog bone fatigue specimen. This motion arises when the specimen is subjected to a cyclic bulk load and then experiences a deformation that the pads do not. Due to the interfacial friction and to the fact that the pads are attached to the apparatus/spring, material points in the pads contact surface are not allowed to displace together with their counterparts in the specimen surface. The reaction of the spring results in the cyclic tangential load, which is hence proportional and iso-frequency to the bulk load. Fig.2 depicts a photo of a test showing the apparatus, a zoom of the specimen/pads mounted in it and a scheme of the contact configuration. 


\subsection{Load configuration and test results.}

A schematic diagram of the loading cycle applied to the fretting configuration is depicted in Fig.2d. After the specimen was mounted on the servo-hydraulic machine, the first step in the loading program was to apply the mean bulk load, so that the load ratio was set to 0 . The fretting pads were then clamped by a constant normal contact load per unit thickness, $P$. The pads used here has a radius of $R=20 \mathrm{~mm}$. This procedure means that the mean load/stress provokes no disturbance on the contact setting. The sinusoidal (fatigue) bulk load, $B$, was finally applied in small steps until the prescribed value for each test. The gradual increase of the bulk load and its frequency is necessary to avoid the pads sliding at the beginning of the test when the coefficient of friction, $f$, is still very low. Therefore, as the shear load is proportional to the bulk load, its increase in steps will allow the slip zones to grow smoothly together with $f$.

To obtain the coefficient of friction, $f$, under the partial slip regime, subsidiary tests were carried out using the methodology presented by Nowell and Hills [17, 18]. The predictions for the slip zone friction coefficient, were between 0.45 and 0.55 . A value of 0.5 was used in the analysis.

The aim of these tests was to find the threshold fretting conditions separating failure from infinite life (here defined by tests which reached $10^{6}$ cycles). To achieve this, the pick pressure, $p_{0}$, was fixed for all tests at $700 \mathrm{MPa}$ (as $P$ and the pad radius are constants), and an initially high fatigue load was decreased from test to test until the run out condition was achieved. Test frequency was fixed to $10 \mathrm{~Hz}$. Here, it should be remarked that the fretting apparatus and the position of the pads along the specimen (the shear load depends not only of $B$ and of the stiffness of the apparatus, but also on the length of the specimen above the contact line [16]) were defined so that the ratio between the bulk and the tangential force $B / Q$ was set to be around 10 . Fig.3 contains the experimental points in a $\sigma_{B} / p_{0} \times Q / f P$ diagram. Notice that the threshold loading is somewhere between $0.121<\sigma_{B} / p_{0}<0.129$ and $0.48<Q / f P<0.53$. Also worth of notice is the fact that for each of these limiting values of this $\sigma_{B} / p_{0}$ range, at least three tests were carried to evaluate the repeatability of such conditions.

Further, in this case, the readers can observe that for the same $\sigma_{B} / p_{0}$ these tests have slightly different values for $Q / f P$. This is mainly due to the fact that it is not possible to guarantee from test to test that the pads will be placed at the same position along the specimen length and this will interfere in the measured value of the shear load. Table 2 reports the salient parameters for the tests carried out and the registered lives.

As follows, one will assume that the threshold condition between complete fracture of the specimen and run out is obtained by setting $Q / f P=0.51, \sigma_{B} / p_{0}=0.125$.

\subsection{Post failure investigation.}

From fracture surface observations under a spectrum electron microscopy (SEM), the crack initiation and growth mechanisms for the fretting fatigue conditions here imposed were investigated. Figure 4a shows an example of the damage caused on the specimen surface by the fretting mechanism, which is typical from the partial slip regime. It is clear there are two slip/fretted zones around a preserved/stick zone. Crack initiation invariably started inside of the fretting damage zones (slip zones) from any of the two sides of the specimen. Further, multiple cracks initiation usually occurred within one of these slip zones somewhere close to the trailing edge of the contact, as illustrated in Figs 4b and 4c. Initially, these cracks grew for a very short distance in a plane nearly perpendicular to the axial main fatigue load direction and then perpendicular to it, until they formed one crack front (see Figs 4c and 4d). The inclination of the crack initiation plane 
was quantified by using a keyence microscope (Fig.4d). The crack plane usually formed an angle with the specimen surface, which varied between $100^{\circ}$ and $115^{\circ}$. The transition to a mode I crack growth occurred after the crack reached a size varying between $40 \mu \mathrm{m}$ and $100 \mu \mathrm{m}$. 
Table 1: Ti-6Al-4V properties used for the analysis.

\begin{tabular}{lllll}
\hline Young Modulus & $\nu$ & $\Delta K_{t h_{R=-1}}$ & $\sigma_{f_{R=-1}}$ & $\tau_{f_{R=-1}}$ \\
\hline $119.4 G P a$ & 0.29 & $5.5 M P a . m^{1 / 2}$ & $583 M P a$ & $411 M P a$ \\
\hline
\end{tabular}

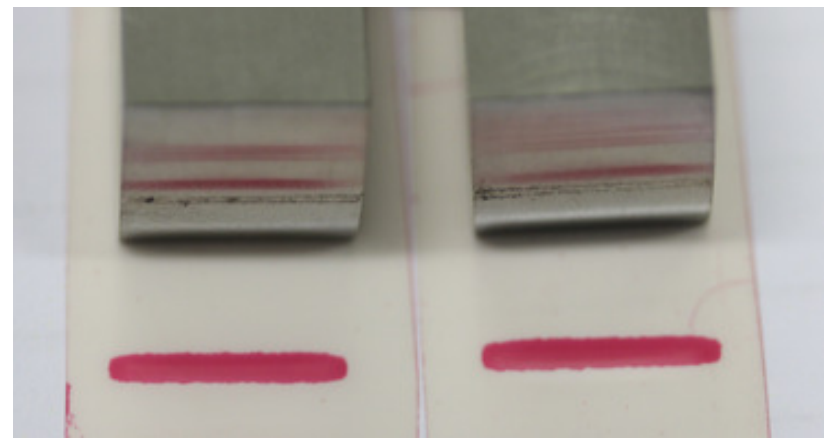

Figure 1: Set of pads with their respected prints on the pressure sensitive paper.

Table 2: Test parameters and results.

\begin{tabular}{|c|c|c|c|}
\hline Test & $\sigma_{B} / p_{0}$ & $Q / f P$ & Nb cycles \\
\hline 1 & 0.114 & 0.464 & 1000000 \\
\hline 2 & 0.142 & 0.566 & 358681 \\
\hline 3 & 0.128 & 0.503 & 593547 \\
\hline 4 & 0.125 & 0.512 & 1000000 \\
\hline 5 & 0.128 & 0.536 & 509677 \\
\hline 6 & 0.121 & 0.492 & 1000000 \\
\hline 7 & 0.128 & 0.529 & 775445 \\
\hline 8 & 0.121 & 0.500 & 1000000 \\
\hline 9 & 0.136 & 0.553 & 645763 \\
\hline 10 & 0.121 & 0.489 & 1000000 \\
\hline
\end{tabular}



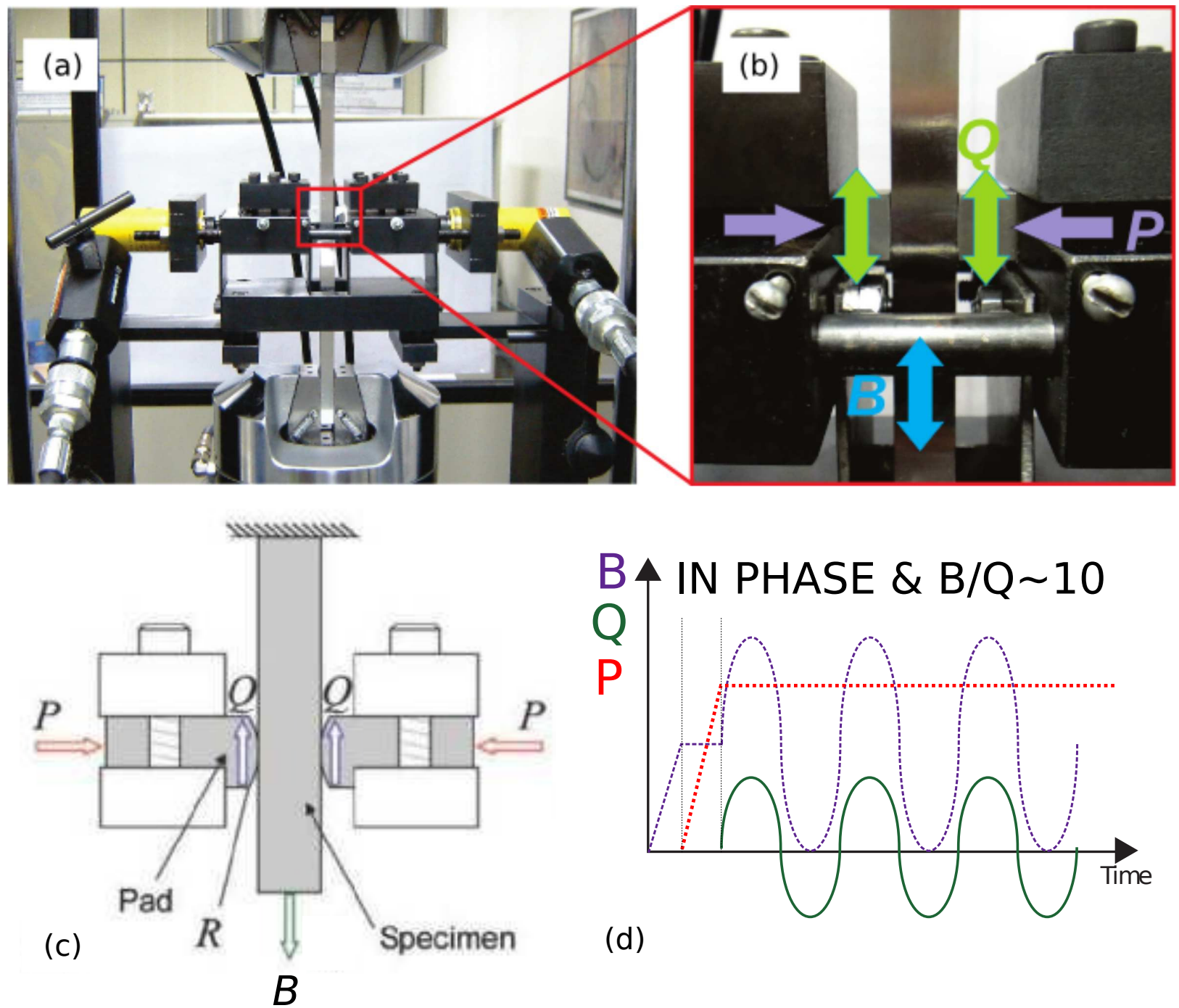

(d)

Figure 2: a) photo of the apparatus b) zoom of specimen/pad contact c) scheme of contact configuration [16], d) diagram of the loading cycle. 


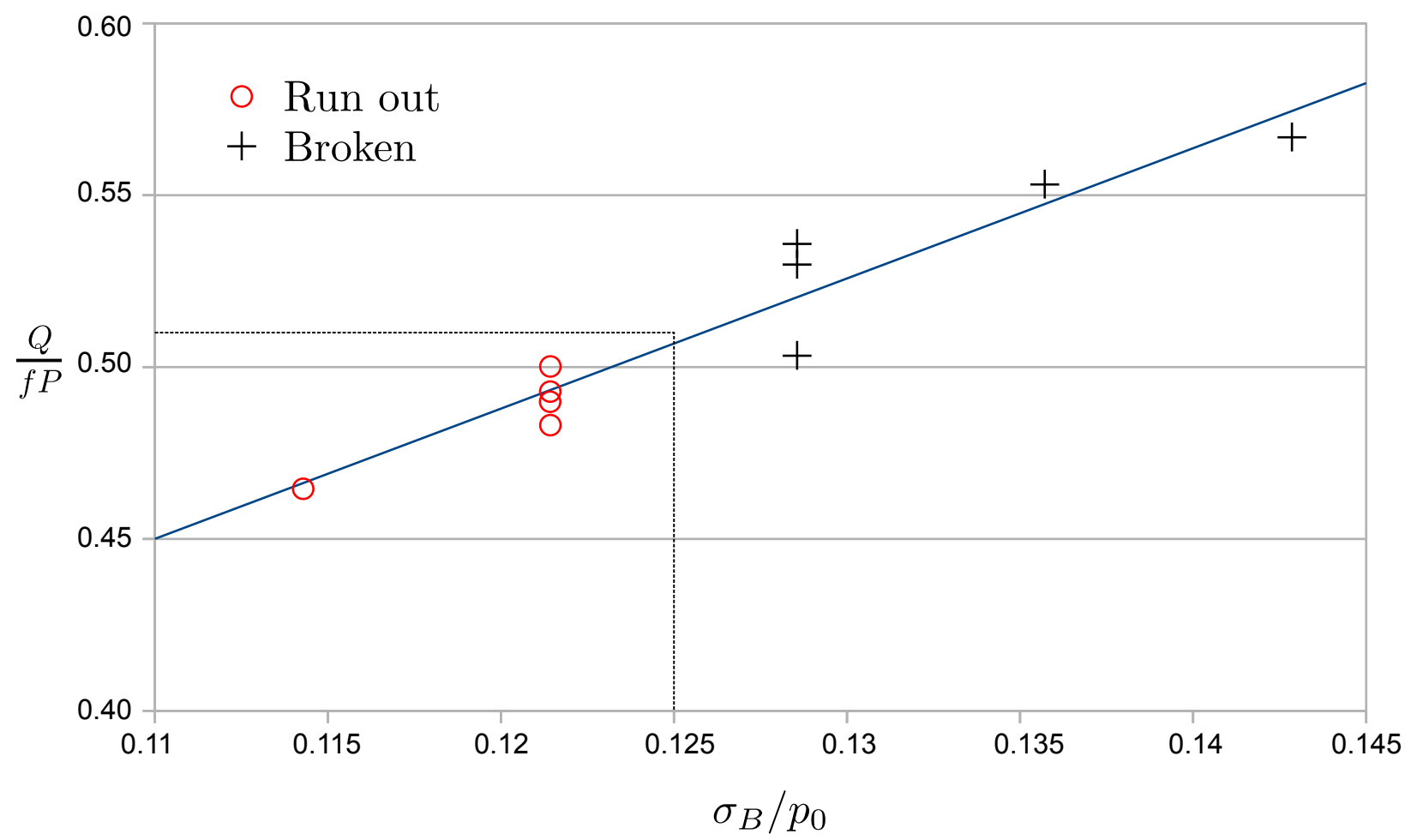

Figure 3: Experimental result, determination of the limit broke/last $10^{6}$. 

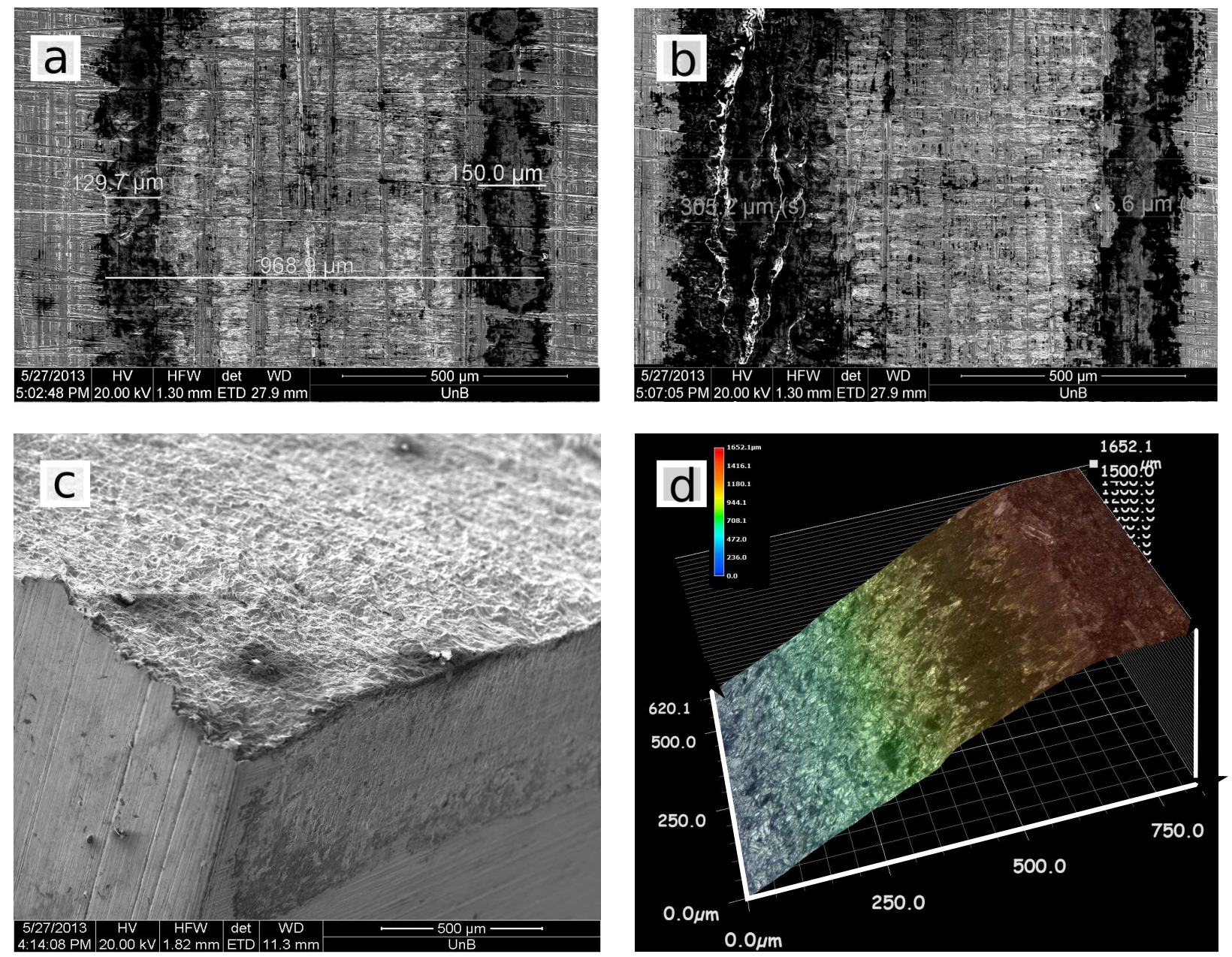

Figure 4: SEM photos tests of Table 2 a) A typical fretting-fatigue mark on a unbroken specimen (test 1) b) Unbroken specimen at $10^{6}$ cycles with presence of multiple crack initiation (test 4) c) fracture surface of a crack which initiates close to the trailing edge of the contact (test 3) d) Crack inclination study using a confocal optical microscope (test 5 , initial angle of $110^{\circ}$ ). 


\section{T-stress}

The Williams solution [19] describes the stress state at any material point ahead the crack tip for an isotropic elastic material. It can be expressed as:

$$
\sigma_{i j}(r, \theta)=A_{1} r^{-1 / 2} f_{i j}^{1}(\theta)+A_{2} f_{i j}^{2}(\theta)+A_{3} r^{1 / 2} f_{i j}^{3}(\theta)+\ldots
$$

where $r$ and $\theta$ are polar coordinates centred at the crack tip. Functions $f_{i j}^{n}$ can be normalised so that $A_{1}$ is defined as the stress intensity factor, $K$, and $A_{2}$ represents a uniform, non-singular stress, $T$. At the crack tip and within a region whose size is of the same order of the size of the plastic zone, the third and higher order terms are still negligible but not $K$ and $T$. As a matter of fact, for such small region a two parameter formulation (K-T) has been shown to describe the fracture process better than the K based approach for several cracked geometries [20, 21].

To clarify the significance of the $T$-stresses, let us consider a media subjected to a biaxial stress tensor $\mathbf{S}^{\infty}$. Let now consider that a small crack with a length $2 a$ is inserted in that media, lying in the plane normal to y and with its straight front directed by $\mathbf{z}$. In linear elastic conditions, the solution of this problem can be obtained by superposition (Fig.5). At the crack tip, the mode I exact solution corresponds to an equibiaxial plane strain loading case. Within a boundary of approximately the size of plastic zone, the $T$-stress component is then superimposed to the mode I plane strain solution to restore the non-equibiaxial remote loading condition. Expressions of the $T$-stresses for various crack geometries and non-uniform loading cases can be found in the literature [22][23], or can be determined from FE computations using fracture mechanics routines. The contribution of the $T$-stress to the crack tip stress and strain fields is usually neglected because long cracks are considered. However, it becomes non-negligible when short cracks are considered.

\section{Generalized von Mises yield criterion}

\subsection{Assumptions}

The criterion used in this paper is a generalized von Mises yield criterion for the crack tip region proposed by Thieulot-Laure et al. [4] and later modified by de De Moura Pinho et al. [5]. The material is assumed to contain small cracks.

The criterion is based on the assumption that fatigue cracks propagate if cyclic plastic strain is experienced at crack tip. The criterion is thus expressed as a threshold for plastic yield for a region of material located within a distance $\delta$ to the crack tip and per unit of length of the crack front. This radius $\delta$ is a length scale parameter to be identified from experiments.

The yield criterion for the crack tip region is obtained as follows. The material is assumed to obey the von Mises yield criterion at the local scale. The von Mises criterion is a critical distortional elastic energy density criterion. In order to calculate the distortional elastic energy density within the crack tip region [4],[24],[5], the stress, strain, and displacement fields at crack tip from LEFM are used. In addition, since it is aimed at using this criterion for small cracks, higher-order terms (T-stresses) in the asymptotic LEFM development are also considered. 


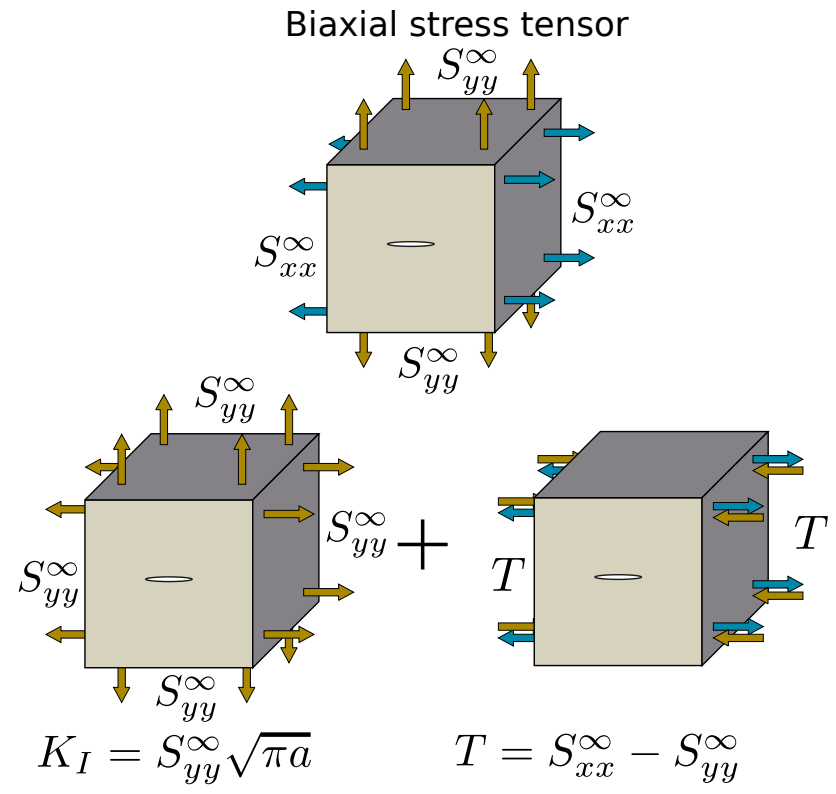

Figure 5: Illustration of the significance of the $T$-stress components in plane strain. 


\subsection{Expression of the criterion.}

In plain strain condition, the asymptotic development [19] at the crack tip of the displacement field $\mathbf{u}$ including the $T$-stress is as follows.

$$
\begin{aligned}
u_{x}= & \frac{K_{I}}{2 \mu} \sqrt{\frac{r}{2 \pi}} \cos \frac{\theta}{2}(\kappa-\cos \theta)+\frac{T}{8 \mu}(\kappa+1) r \cos \theta \\
& +\frac{K_{I I}}{2 \mu} \sqrt{\frac{r}{2 \pi}} \sin \frac{\theta}{2}(\kappa+2+\cos \theta) \\
u_{y}= & \frac{K_{I}}{2 \mu} \sqrt{\frac{r}{2 \pi}} \sin \frac{\theta}{2}(\kappa-\cos \theta)-\frac{T}{8 \mu}(3-\kappa) r \sin \theta \\
& -\frac{K_{I I}}{2 \mu} \sqrt{\frac{r}{2 \pi}} \cos \frac{\theta}{2}(\kappa+2+\cos \theta) \\
u_{z}= & 0
\end{aligned}
$$

where $2 \mu=E /(1+\nu)$ and $\kappa=3-4 \nu$. Using cylindrical coordinate system, the strain tensor $\varepsilon$ is derived from the displacement field $\mathbf{u}$, and the stress tensor $\sigma$ is obtained by the Hooke's law. The distortional elastic energy density $w(r, \theta)$ at each point $(r, \theta)$ is then obtained:

$$
w(r, \theta)=\frac{1}{2} \operatorname{Tr}\left(\sigma^{\prime} \cdot \varepsilon^{\prime}\right)
$$

where $\sigma^{\prime}$ and $\varepsilon^{\prime}$ are the deviatoric parts of the stress and strain tensors. The distortional elastic energy density is then integrated over a domain within a distance $\delta$ to the crack tip, to get the distortional energy per unit of length of the crack front $U\left(K_{I}, K_{I I}\right)$ :

$$
U\left(K_{I}, K_{I I}, T\right)=\int_{0}^{\delta} \int_{-\pi}^{\pi} w(r, \theta) r d \theta d r
$$

The yield criterion is finally expressed as follows:

$$
U\left(K_{I}, K_{I I}, T\right)=U_{C}
$$

Where $U_{C}$ is a critical distortional elastic energy per unit of length of the crack front, which is determined with the additional assumption that crack growth stems from crack tip plasticity. In such a case, the threshold stress intensity factor for long cracks can be used to determine a yield threshold $K_{I Y}$ so that:

$$
U_{C}=U\left(K_{I}=K_{I Y}, K_{I I}=0, T=0\right)
$$

A few mathematical simplifications of eq. 5 allow expressing this criterion as follows: 


$$
f=\left(\frac{K_{I}}{K_{I Y}}\right)^{2}+\left(\frac{K_{I I}}{K_{I I Y}}\right)^{2}+\left(\frac{T}{T_{Y}}\right)^{2}+f_{1} \frac{K_{I}}{K_{I Y}} \frac{T}{T_{Y}}-1=0
$$

The analytic formulation of the other coefficients are reported in Table 3.

\subsection{Identification of the parameters}

This yield criterion requires three material parameters, $K_{I Y}, \nu$ and $\delta$. In a first time, the mode I threshold stress intensity factor for long cracks can be used to determine a yield threshold $K_{I Y}$ Eq. 8.

$$
K_{I Y}=\Delta K_{t h_{R-1}} / 2
$$

As the Poisson's ratio $\nu$ is known, remain the identification of the parameter $\delta$ in the nonpropagation criterion.

Let us consider, for instance, a through thickness crack lying in the plane $(x, z)$ and subjected to remote uniaxial loads which amplitudes are $S_{y y}^{\infty}$, the expressions of mode I SIF and $T$-stress are the following:

$$
\begin{aligned}
& K_{I}=S_{y y}^{\infty} \sqrt{\Pi a} \\
& T=-S_{y y}^{\infty}
\end{aligned}
$$

Under uniaxial loading conditions, for instance, the threshold for crack propagation can be easily calculated as a function of the crack length using Eqs. 9 and 7. Its evolution can be plotted in a Kitagawa-Takahashi type diagram for various values of the dimension $\delta$ of the integration domain. Fig.6 illustrates an example of growth threshold using two values of $\delta$.

The criterion predicts that the yield threshold is increasing with the crack length up to the saturation value $K_{I Y}$. The saturation rate increases with the value of $\delta$.

Then if we have access to a Kitagawa-Takahashi type diagram from experimental test [25][26][27], the dimension $\delta$ can be identified as illustrated in Fig.6.

De Moura Pinho et al. [5] used another method to identify the parameter $\delta$ for the same Ti64 alloy used in the experimental campaign here. This method required the fatigue limits in alternated tension $\left(\sigma_{f}\right)$ and in alternated torsion $\left(\tau_{f}\right)$ to identify an equivalent flaw size $\left(b_{0}\right)$ and the parameter $\delta$. They showed that the value of $\left(\delta / b_{0}\right)$ is a function of the ratio between $\sigma_{f}$ and $\tau_{f}$. The value of $\delta=1 \mu \mathrm{m}$ considered for the following analysis was collected from De Moura Pinho et al. [5].

\subsection{Representation of the criterion.}

In Fig.7, by way of illustration, the criterion is plotted in a $K_{I}-T-K_{I I}$ diagram. According to Eq. 7, the yield criterion is an ellipsoid in this diagram. Inside the ellipse, the material within the crack tip region behaves essentially elastically and the crack is assumed to remain arrested. Loading paths corresponding to two crack lengths were plotted for a Griffiths crack (2D plane strain) subjected to a uniaxial tensile stress (i.e. $K_{I}=S_{y y}^{\infty} \sqrt{\Pi a}$ and $T=-S_{y y}^{\infty}$ ). When the loading path meets the yield surface, crack tip plasticity and hence crack propagation is expected to occur. The frontier marked by open squares corresponds therefore to the evolution of the threshold stress intensity factor with the crack length. Various loading paths including multi-axial non-proportional 


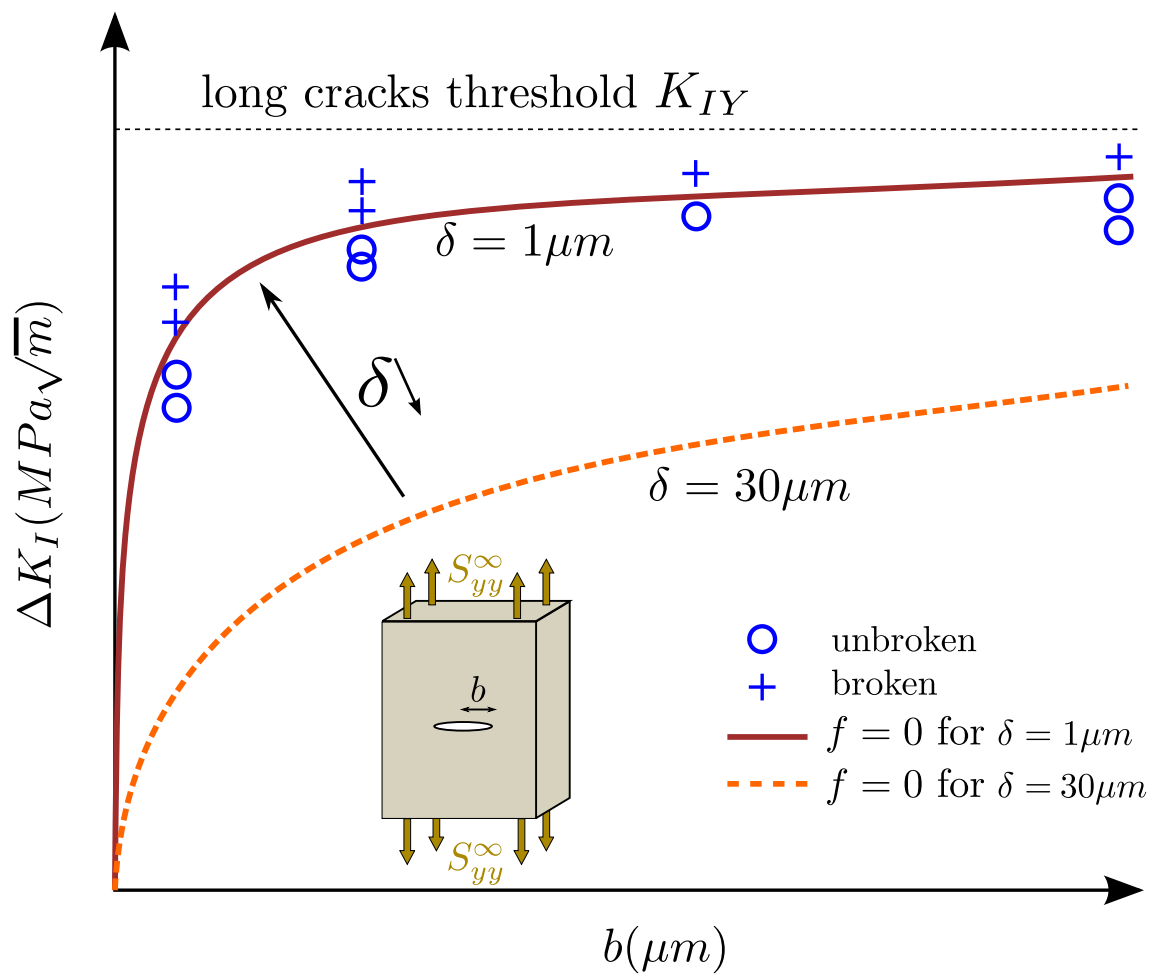

Figure 6: Case of a through thickness crack in an infinite media. Schematic evolution of the non propagation threshold, as calculated using the criterion, versus the crack length, for various values of $\delta$. Illustration of $\delta$ identification using experimental test. 
cases can be considered. If the loading path remains inside the elastic domain, the crack should remain arrested.

In addition, if crack growth stems from crack tip plasticity, we may assume that the crack growth rate could be roughly estimated using $f$. Hence, we can define a index using the function $f$.

$$
\text { Index }=\left.\int_{t \in T}\left(\frac{d f_{>0}}{d t}\right)_{>0} d t\right|_{K_{I}>0}
$$

Indeed, it is assumed here that uniquely the segment of the cycle where the crack is open can generate plasticity at the tip of the crack. Then, during each fatigue cycle, different phases may appear. During a loading step, $f$ is first negative (elasticity) then becomes positive above the yield threshold (plasticity occurs). Then, at unloading, $f$ is positive but $d f$ is negative.

The effective part of the loading cycle is thus the integration of $d f$ over the fatigue cycle, considering only the time steps during which plasticity is promoted i.e. the time steps during which both $f$ and $d f$ are positive.

In addition, if crack growth stems from crack tip plasticity, we may assume that the crack growth rate could be roughly estimated using this index [28][29].

$$
d a=\alpha\langle d\langle f\rangle\rangle^{\gamma}=\alpha(\text { Index })^{\gamma}
$$

with, for this material, $\alpha=9.10^{-10}$ and $\gamma=1$ [28]. 
Table 3: Coefficients in Eq. 7 calculated for a Poissons ratio $\nu=0.29$.

\begin{tabular}{ccc}
\hline$K_{I I Y}$ & $T_{Y}$ & $f_{1}$ \\
\hline$K_{I Y} \sqrt{\frac{7-16 \nu+16 \nu^{2}}{19-16 \nu+16 \nu^{2}}}$ & $\frac{K_{I Y}}{\sqrt{2 \Pi \delta}} \frac{1}{2} \sqrt{\frac{7-16 \nu+16 \nu^{2}}{1-\nu+\nu^{2}}}$ & $\frac{32\left(1-10 \nu+10 \nu^{2}\right)}{15 \Pi \sqrt{\left(1-\nu+\nu^{2}\right)\left(7-16 \nu+6 \nu^{2}\right)}}$ \\
\hline $0.48 K_{I Y}$ & $\frac{0.43 K_{I Y}}{\sqrt{\delta}}$ & -0.419 \\
\hline
\end{tabular}

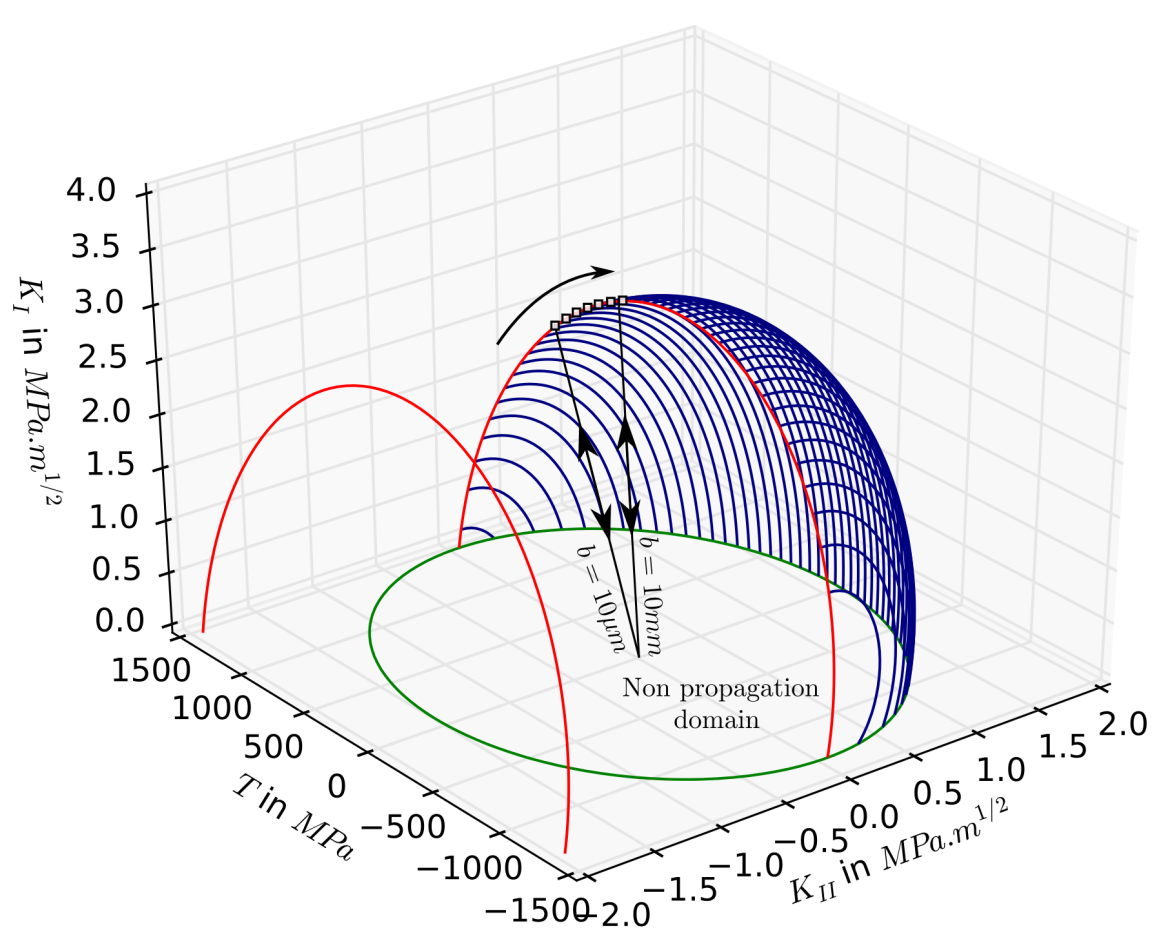

Figure 7: Criterion in Eq. 7 identified for the Ti-6Al-4V titanium alloy plotted in a $K_{I}-T-K_{I I}$ diagram for $\delta=1 \mu \mathrm{m}$, for a Griffiths crack in traction, in plane strain condition. The solid lines indicate the loading paths obtained for different crack lengths when $S_{x x}=0$. 


\section{Application to fretting}

In this section, the T-stress based criterion will be applied to the fretting fatigue configuration considered in our tests. The linear elastic fracture mechanics quantities ( $K_{I}, K_{I I}$ and $T$-stress) were calculated using the finite element method (FEM). Details of the FEM model are provided below (Sec.5.1). Two different possibilities for crack growth modeling were evaluated. In the first case, Sec.5.2, the crack path is constrained and assumed to be perpendicular to the axial fatigue load direction. Later, Sec.5.3, a more flexible modeling is experienced, where the T-stress based criterion not only evaluates the crack advance risk but also defines its path.

\subsection{FEM modeling of the fretting-fatigue}

This fretting-fatigue configuration is modeled with finite elements using the commercial software ABAQUS. The model is 2D and use linear quadratic plane strain elements. Only one contact between the pad and the specimen is modeled. Symmetric boundary conditions are defined on the middle axis of the specimen. The general boundary conditions and the load applied are illustrated in Fig.8.

The element size away from the contact interface is $500 \mu \mathrm{m}$, and in the contact zone the refined mesh required $8 \mu \mathrm{m}$ elements. Another structured refinement is used at the tip of the crack in order to have good estimation of the linear elastic fracture mechanics quantities after few contours integral evaluation [30].

In this modeling, the same interaction property has been used to describe the contact pad/specimen and the contact between crack faces. Contact properties are:

- Normal behaviour: hard contact using Lagrange constraint enforcement method,

- Tangential behaviour: penalty friction formulation.

This choice will be discussed in the last section of the article.

\subsection{Straight crack.}

As a first application of this criterion to fretting fatigue, let us consider a crack initiating at the trailing edge of the contact. This crack is assumed to grow perpendicular to the axial fatigue load direction. The configuration adopted is the same defined in the Sec.2: pad radius $20 \mathrm{~mm}$, $Q / f P=0.51$ and $\sigma_{B} / p_{0}=0.125$. In this condition the stick/slip zone size ratio gives $c / a=0.7$. The time varying stress intensity factors and T-stress were computed for different crack sizes. As a example, the stabilized time history of $K_{I}, K_{I I}$ and $T$ for a crack length $b=5 \mu m$ is reported in Fig 9. It can be seen that, for this straight crack, the mode I is logically dominant $\left(K_{I}>>K_{I I}\right)$.

Figure 10 shows the time history of the linear elastic fracture mechanics quantities for the $35 \mu \mathrm{m}$ crack and the yielding surface defined by the function $f$. In this case, the curve of the history exceeds the yielding surface, crack growth is then expected.

Fig.11 illustrates the influence of the $T$-stress on the criterion. Each point in this graph represents the relative value of the terms containing the $T$-stress on the criterion (eq.7), for a specific crack size. It seems clear from such figure that the influence of the $T$-stress is high for small cracks. For instance, for a $5 \mu \mathrm{m}$ crack, the terms containing the $T$ stress account for approximately $30 \%$ of the index, and of course, when the crack grows, his effect vanishes progressively.

Fig.12 shows the index $\langle d\langle f\rangle\rangle$ for different vertical crack sizes $b$ at different points under the slip zone. According to this plot, at the trailing edge of the contact $(x / a=-1)$, a $10 \mu m$ defect is 
necessary to generate plasticity at the tip of the vertical crack and hence to propagate this short defect under these loading conditions. For the other three cracks, the minimum size necessary for the crack to grow (observe a positive index) is even higher. To sum up, when a vertical crack is assumed, the loads involved in this study would require the existence of cracks larger than $10 \mu m$ if they were to propagate. Moreover, post failure investigation of the fretting specimens has revealed inclined cracks, which vary between $100^{\circ}$ and $115^{\circ}$. In the following, the effect of the crack orientation on the growth prediction will be examined.

\subsection{Inclined crack.}

\subsubsection{Path research algorithm.}

In the present work, the analysis has been extended with a research of the crack angle maximizing the criterion of eq.10. The initiation point of the crack is however still assumed to be at the edge of the contact.

A Python script allows the automatic creation of an Abaqus model, including a crack, and a post-treatment of the results. The algorithm may be described as follows.

At the first step, a set of models are generated. Each of these models include a short crack with same size but with a different orientation. Using the time history of the linear elastic fracture mechanics quantities obtained from computation, the index (Eq.10) is computed for each orientations. An adaptive multi-step search algorithm detailed by Norberg and Olsson [31] and illustrated in Fig.13 is used to identify the orientation maximizing the index, and limit at a minimum the number of model evaluated. If the maximum found is positive, it is assumed that the crack will grow, and its direction will be the direction tested which maximized the index.

The process is then repeated for a given number of increments, or stopped if the index becomes negative for all acceptable orientations. The Fig.14 illustrates the first two steps of the procedure.

\subsubsection{Results.}

This methodology has been applied to the relevant loading configurations observed experimentally (Sec.2):

- Case $1 Q / f P=0.55$ and $\sigma_{B} / p_{0}=0.136$ : Specimen brake before $10^{6}$ cycles,

- Case $2 Q / f P=0.49$ and $\sigma_{B} / p_{0}=0.121$ : Specimen survived at $10^{6}$ cycles but crack arrest was observed,

- Case $3 Q / f P=0.45$ and $\sigma_{B} / p_{0}=0.110$ : Specimen survived at $10^{6}$ cycles and not crack no crack initiation was observed,

At the first increment, the orientation of a $5 \mu \mathrm{m}$ crack is analysed. Then the crack size increment in increased to $20 \mu \mathrm{m}$, this size increment allow a good agreement between crack path accuracy and processing time. Note that the crack is still assumed to initiate at the trailing edge of the contact.

As a first observation of the results, Fig.14 presents the results of the angular distribution of the index at the first two increments for Case 2 loading configuration. As observed in the first part of this section, the index was null when the $5 \mu \mathrm{m}$ crack is vertical $\left(\right.$ Angle $=90^{\circ}$ ), however, two peaks with positive values of the index are observed for inclined cracks at $45^{\circ}$ and $140^{\circ}$. Those two peaks present different maximum, indeed, the crack oriented towards the contact zone $\left(140^{\circ}\right)$ induces a highest index. At the second increment, the crack path direction remained roughly the same. It can be noted that the crack orientation estimation is not far from the actual crack path. The time 
history of the linear elastic fracture mechanics quantities are illustrated for this orientation of the $5 \mu \mathrm{m}$ crack in Fig.15, the red part of the curve corresponds to the creation of plasticity at the tip of the crack.

Figures 16 presents the results of the simulation of the three loading cases. In Fig.17, the paths predicted for the loading cases 2 and 3 are presented. An example of crack profile observed at the middle section of the specimen is also given.

For the case 3, the index computed at the first step for all orientations was null. It means that a initial defect of $5 \mu \mathrm{m}$ is not expected to grow with this loading. When the second loading case is considered, the model predicts a short crack grow at $140^{\circ}$. Then the crack path predicted progressively turns to mode I, which was expected. When the crack reaches a size of $140 \mu \mathrm{m}$, crack arrest is predicted.

Indeed, the blue curve in Fig.16 shows a value of the index which increased until 0.8 and then decreased until 0 . This profile is typical from the competition between crack length and stress gradient in fretting problem.

When the third loading case is considered, the crack profile predicted is very similar, but no crack arrest is observed. When the crack reaches a size of $200 \mu m$, the decrease of the state of stress is not sufficient and the crack will continue its growth until failure.

After a certain distance, the crack propagation direction computed remains almost constant to the value $45^{\circ}$. This result disagrees with the experiential observations, where long cracks show a propagation in mode I governed by the bulk load. Figure 18 represents the history of $K_{I}, K_{I I}$ and $T$ in a $3 \mathrm{D}$ graph. The red surface represents the threshold of the elastic zone defined by the function $f=0$. With such history, the index corresponds to the maximum value of the function $f$ during the cycle. The iso-f surfaces in blue confirm the preference for the inclined crack.

Now, attention can be directed to the loading ratio observed at the tip of the crack for those two orientations. For that, the interpenetration of crack faces is allowed. The ratio $K_{I_{\min }} / K_{I_{\max }}$ and $K_{I I_{\min }} / K_{I I_{\max }}$ are given in the Tab.4. The loading ratio at the tip of the crack is significantly different from one orientation to the other. This may explain why the orientation predicted for long crack propagation is so far from the orientation expected.

\subsection{Comparative assessment.}

In order to carry out a comparative analysis, a type of Kitagawa-Takahashi short crack methodology previously tried by other authors $[18,35,34]$ is now considered. A straight crack initiating at the trailing edge of the contact was assumed. To compute the $\Delta K_{I}$ the distributed dislocation technique was used $[38,39]$. The method requires the computation of the stress field along the imaginary line of the crack. In this case, a closed form solution was adopted following the well known procedure described in [36] that combines the Hertz/Mindlin solutions for the calculation of the tractions and the Muskhelishvilli potentials to workout the stress history at each subsurface material point.

$\Delta K_{I}$ computations as a function of the crack length are given in Fig.19 for the previous loading configurations. They are compared with the Kitagawa-Takahashi and the El Haddad threshold lines. For all loading configurations, a decrease of the SIF range is observed after $50 \mu m$. This is caused by the severe stress gradient under the contact and was also observed in the T-based analysis presented previously. For the first loading case $\left(\sigma_{B} / p_{0}=0.136 Q / f P=0.55\right)$, the straight crack at the trailing edge of the contact is expected to grow. Under the second loading case $\left(\sigma_{B} / p_{0}=0.121 Q / f P=0.49\right)$ this analysis fails to predict the crack arrest observed experimentally. In the third case considered, the $\Delta K_{1}$ curve meets the Kitagawa-Takahashi threshold in the short 
1

2

3 crack regime, then short crack arrest is estimated $(b=4.8 \mu m)$. Now, if the El Haddad threshold 


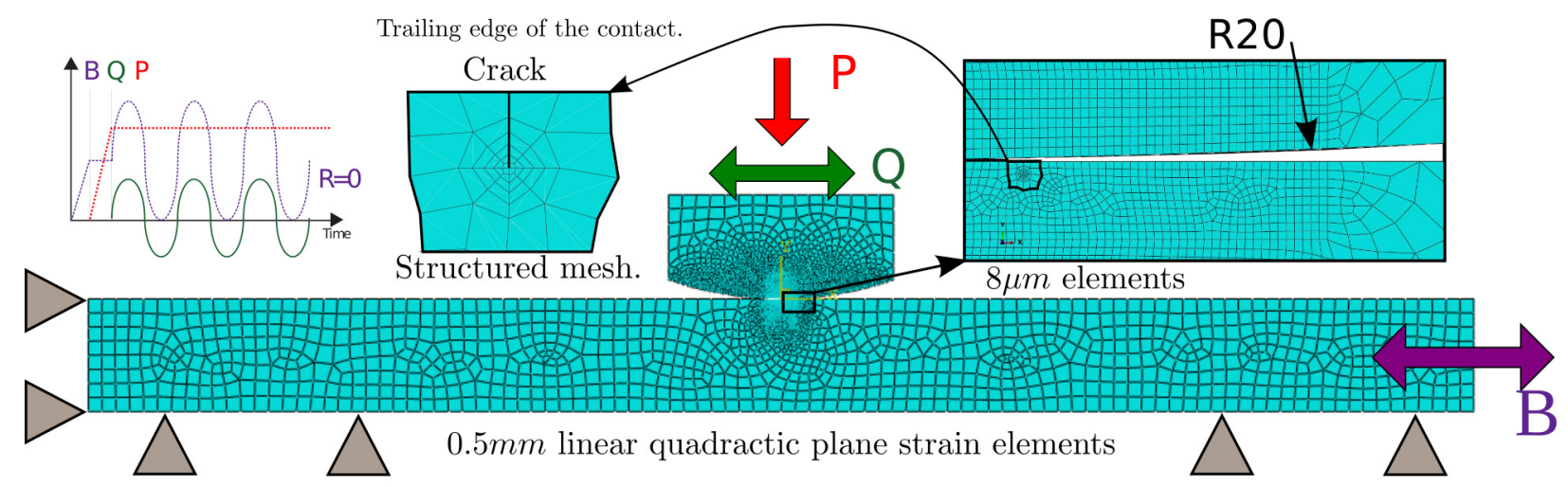

Figure 8: Illustration of the FEM modeling.

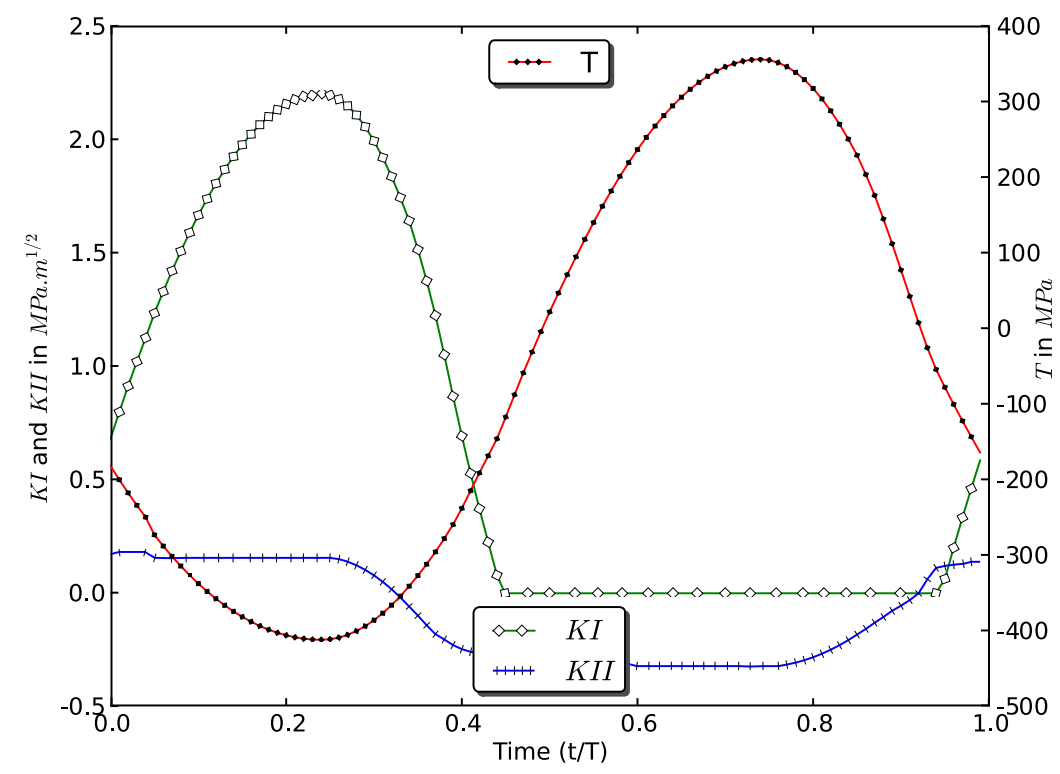

Figure 9: Stress intensity factor and T-stress evolutions during fretting-fatigue cycling at $5 \mu m$ below the surface.

Table 4: Loading ratio at the tip of two crack considered at the $20^{\text {th }}$ increment.

\begin{tabular}{|c|c|c|}
\hline Orientation & $K_{I_{\min }} / K_{I_{\max }}$ & $K_{I I_{\min }} / K_{I I_{\max }}$ \\
\hline $90^{\circ}$ & -0.98 & 0.06 \\
\hline $45^{\circ}$ & -0.55 & -0.93 \\
\hline
\end{tabular}




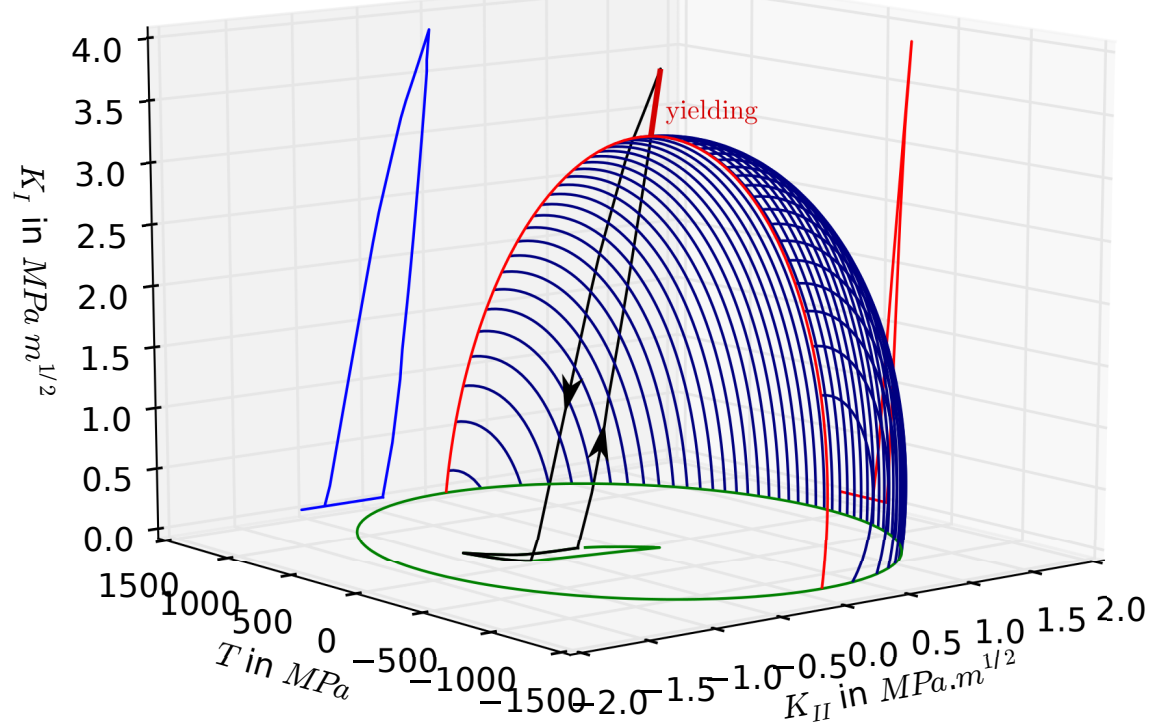

Figure 10: Time history of the linear elastic fracture mechanics quantities for the $35 \mu \mathrm{m}$ crack initiating at the trailing edge of the contact.

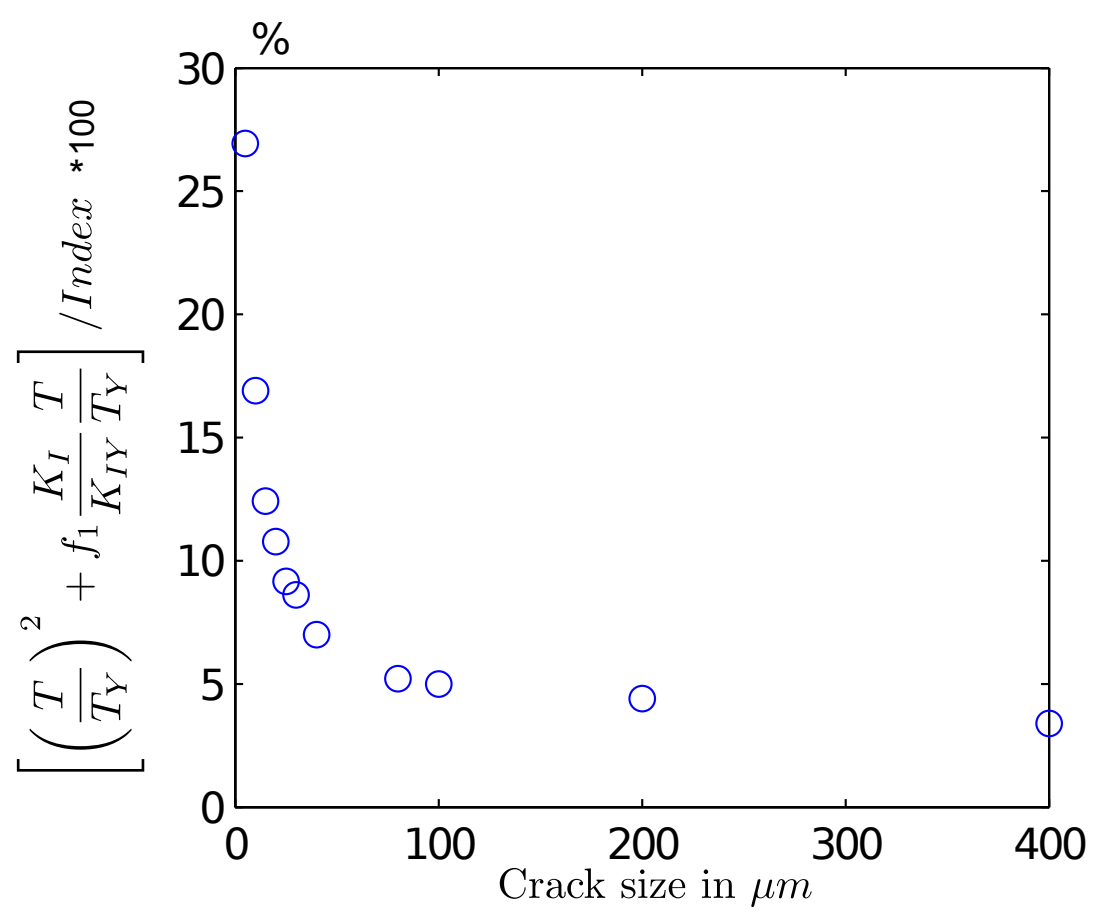

Figure 11: Relative influence of the $T$-stress in the criterion defined by the eq.7, for diferent crack size, using the intergral parameter delta $=1 \mu \mathrm{m}$. 


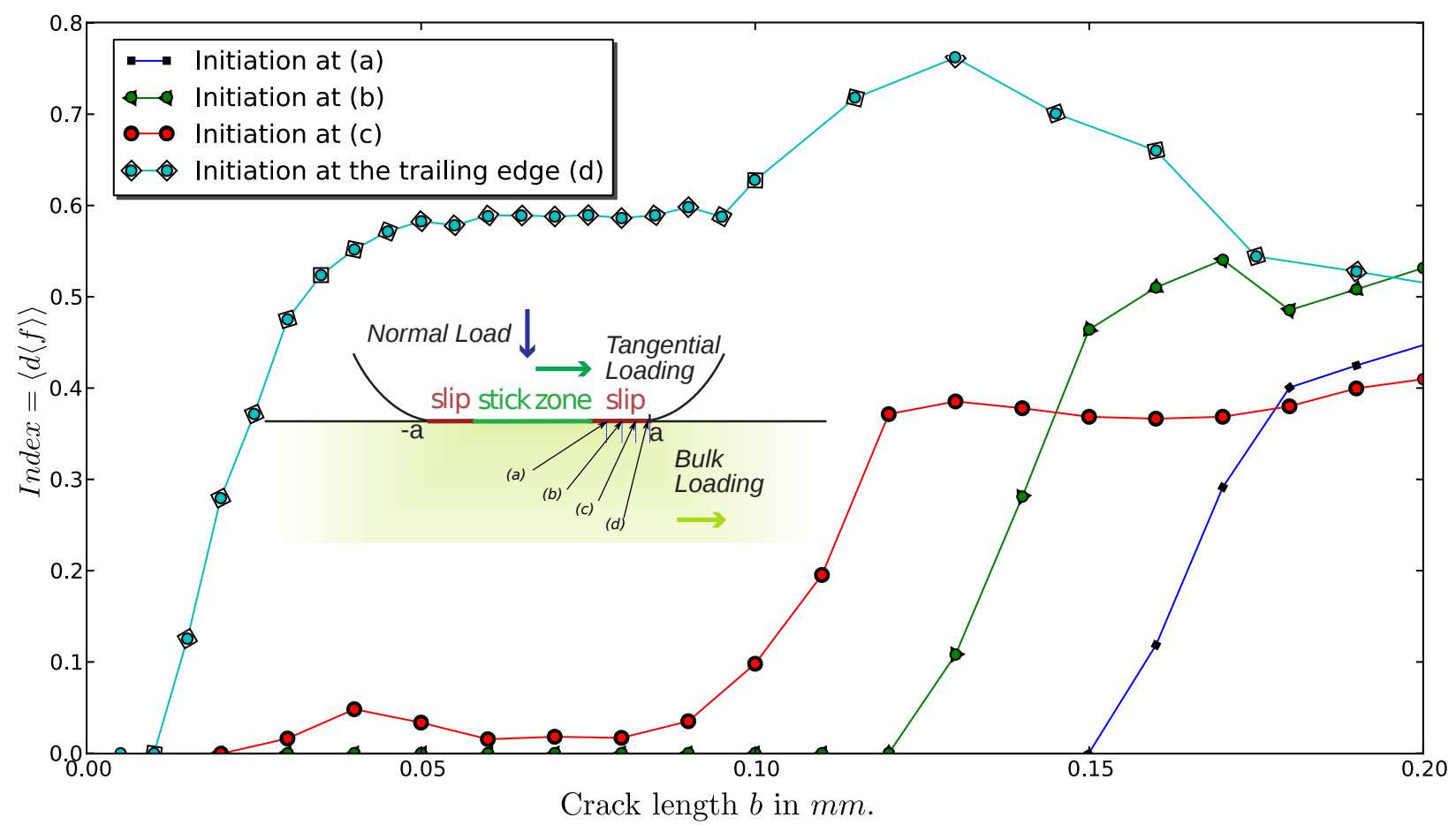

Figure 12: Evolution of the index with length $b$ for vertical cracks initiating from different points under the slip zone. 

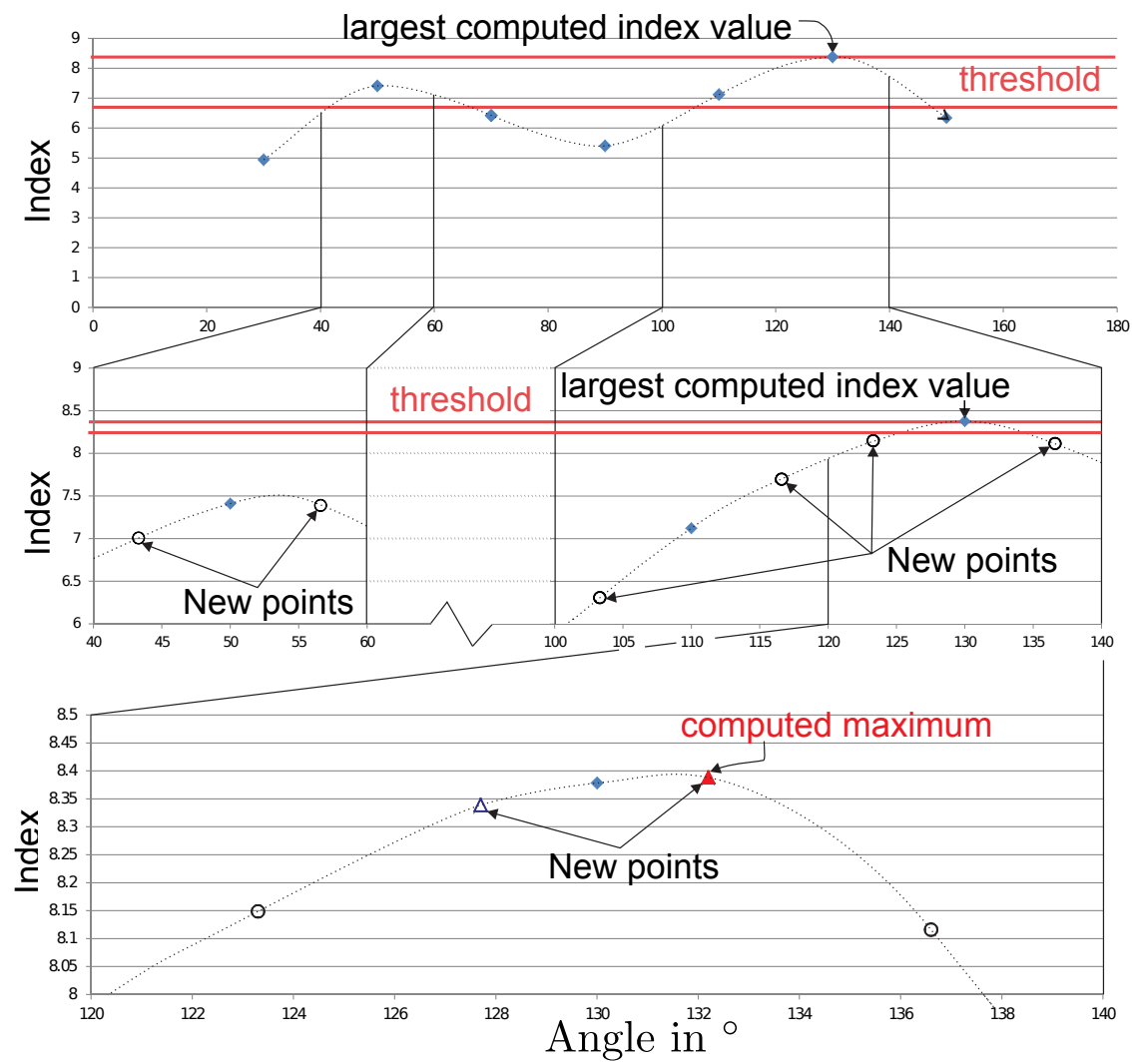

Figure 13: Schematic of the search algorithm used for finding the maximum value of $f$. Two refinement steps take place in the intervals where the extreme value may occur. [31]

a)
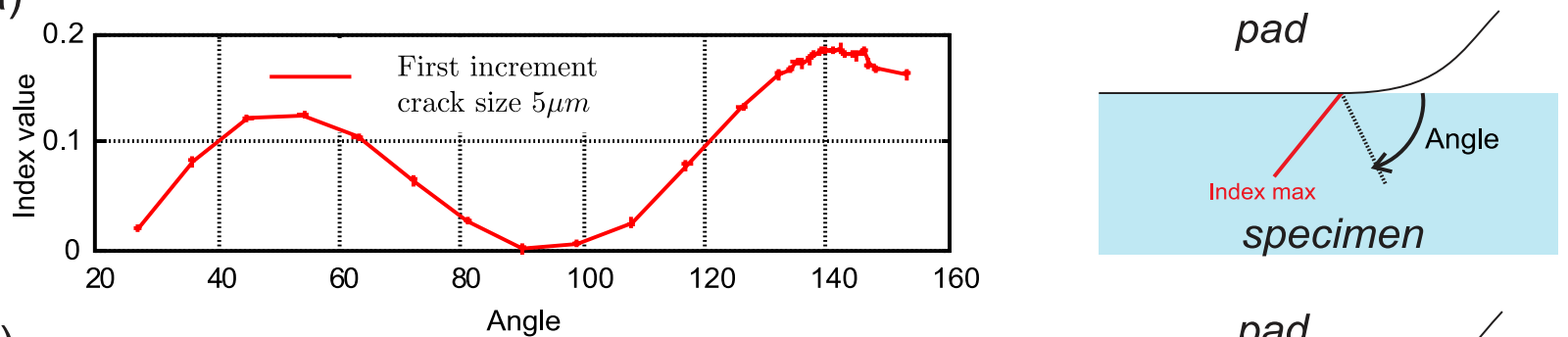

b)
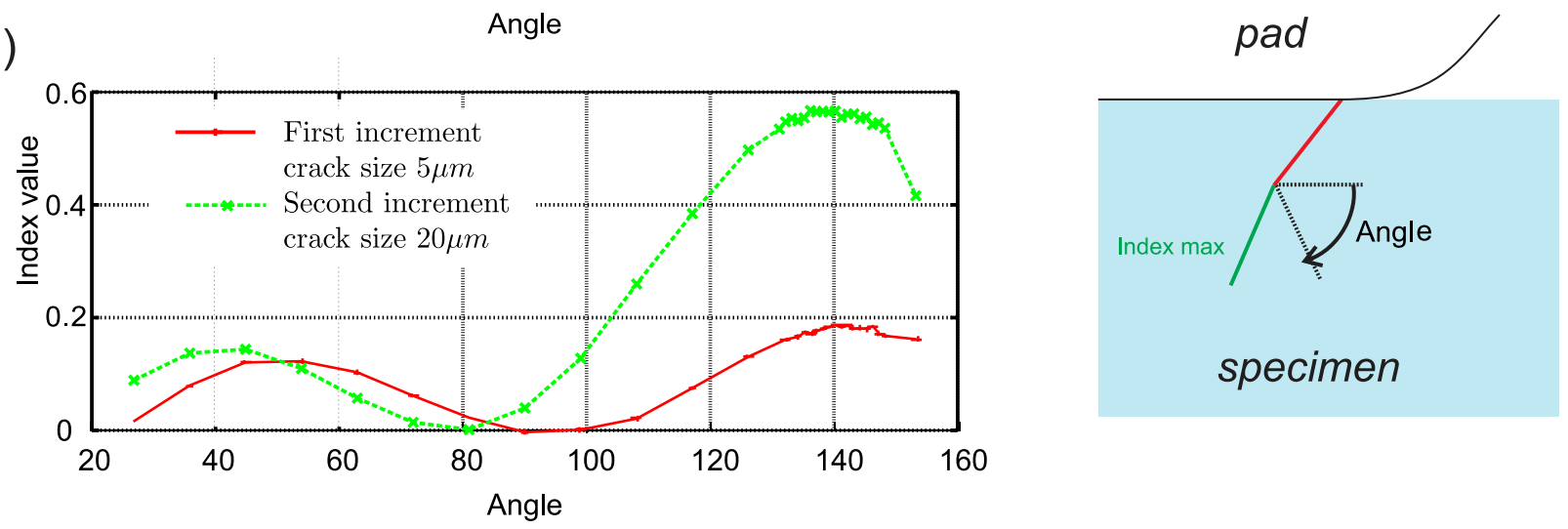

Figure 14: Illustration of the two first increments analyses. 


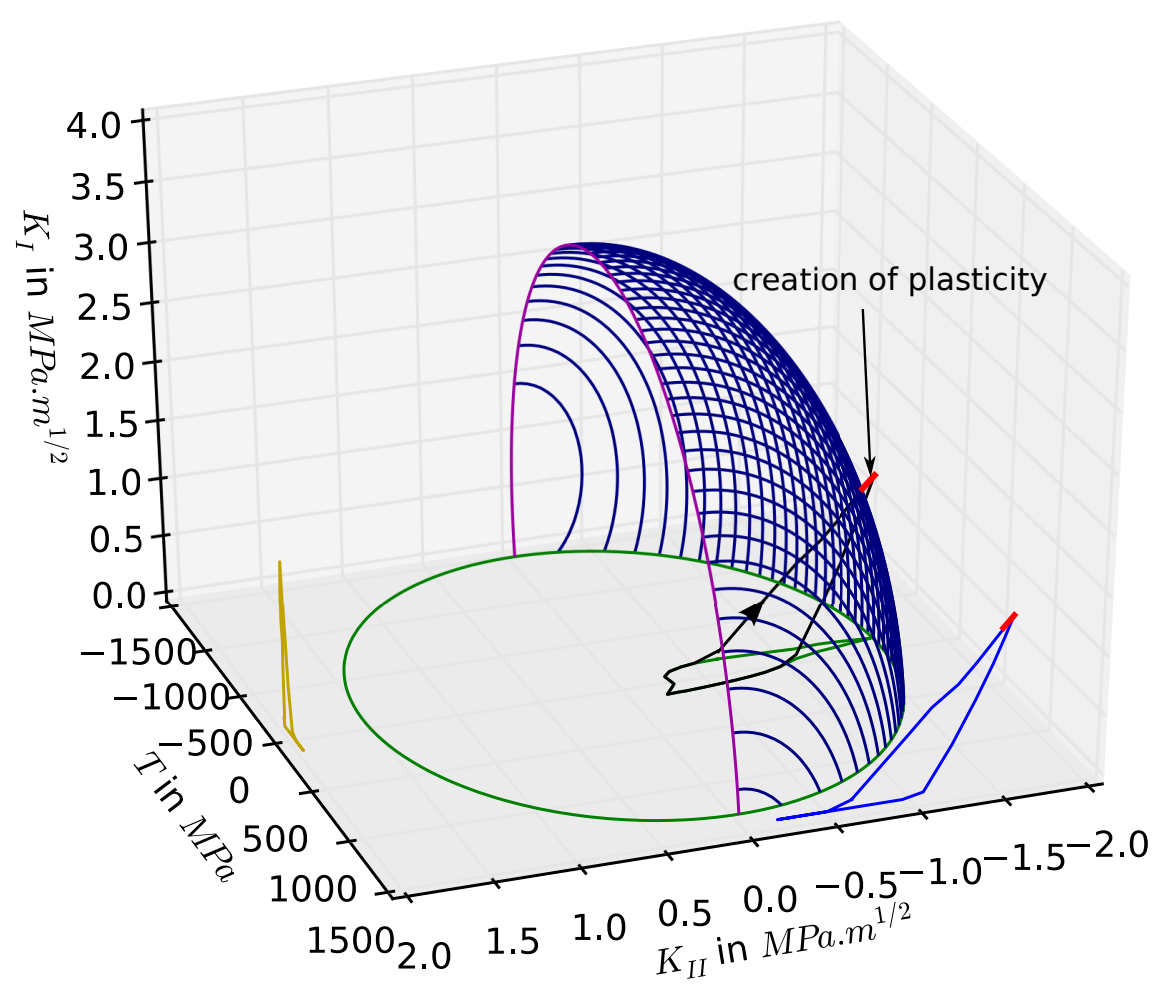

Figure 15: History of the linear elastic fracture mechanics quantities for a $5 \mu \mathrm{m}$ crack, inclined at $135^{\circ}$.

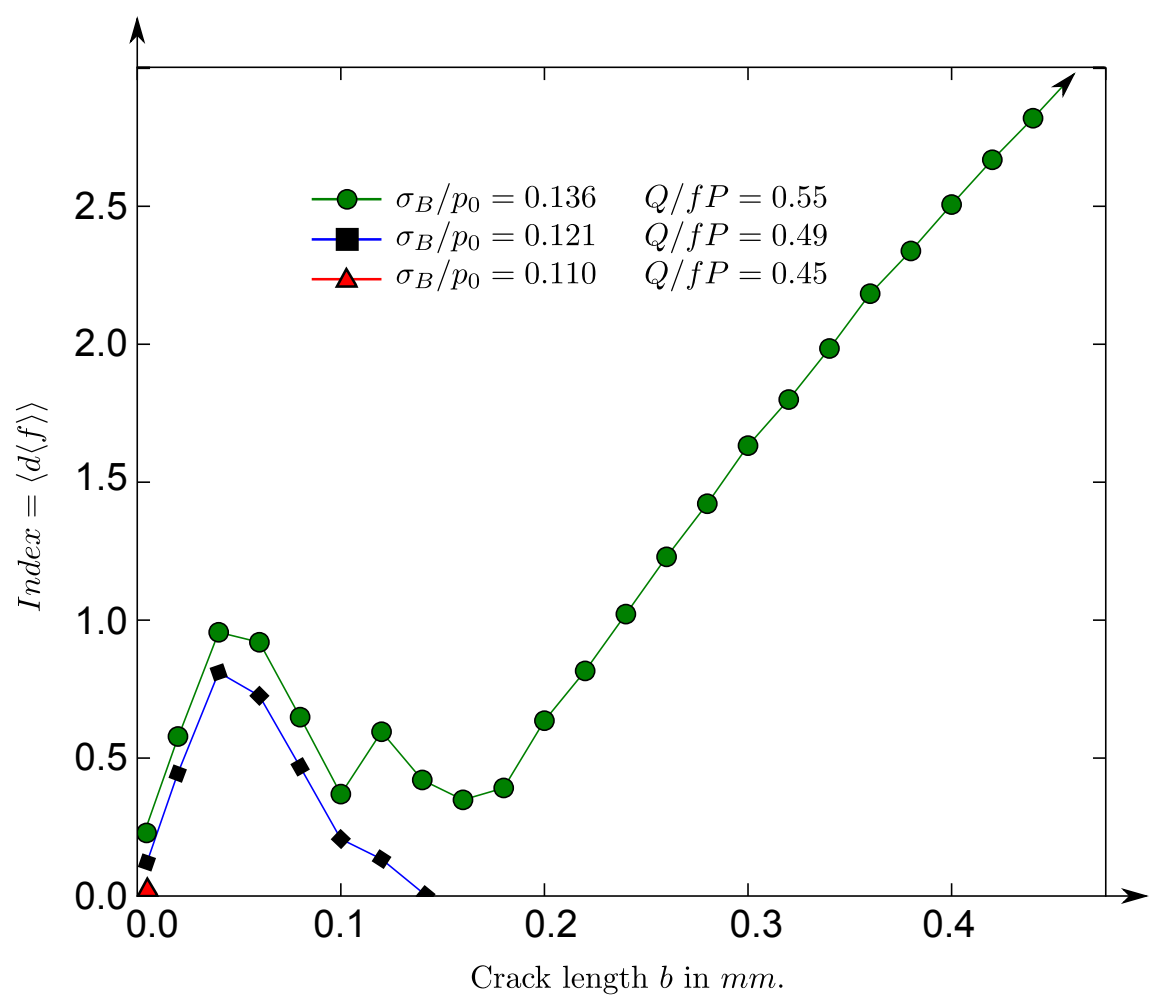

Figure 16: Index computed using the path reshearch algorithm. 
Figure 17: Crack path predicted for the relevant loading configurations. In red, an example of profile of the crack surface, here obtained for test 7 at the middle of the contact width. 


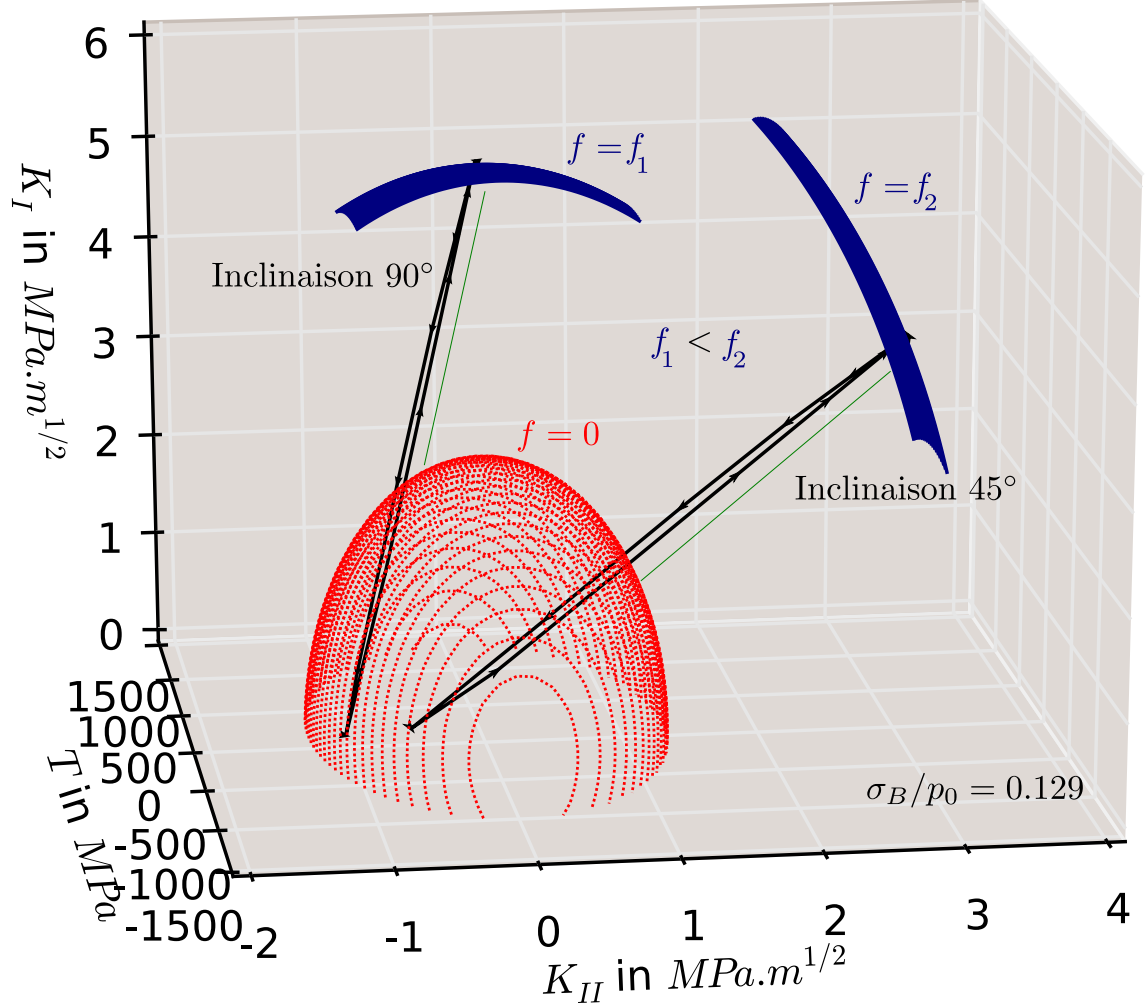

Figure 18: $3 D$ representation of the orientation $45^{\circ}$ and $90^{\circ}$ analysed after 20 increments (crack size $400 \mu m$ ).

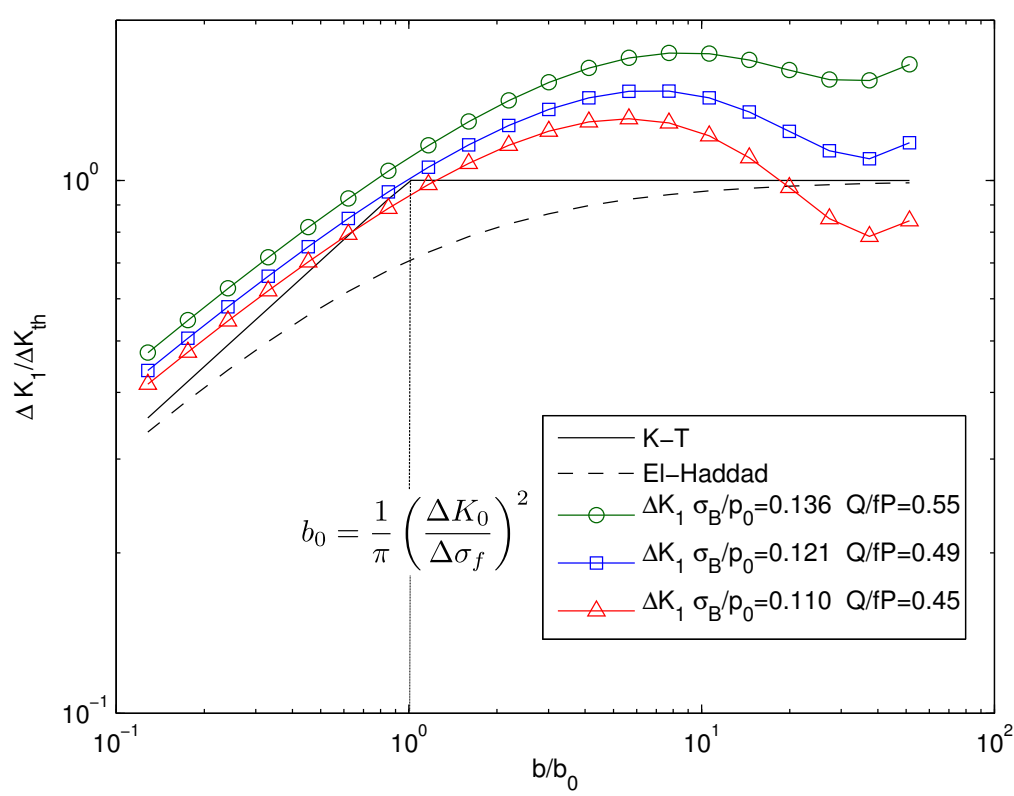

Figure 19: $\Delta K_{I}$ calculated for 3 fretting-fatigue loading configurations and $K-T$ and El Haddad diagram showing the threshold for crack propagation. 


\section{Discussions and conclusions.}

A preliminary experimental study was performed to investigate high cycle failure induced by elastic fretting fatigue cylinder/plane contact for a fixed contact pressure and a range of fatigue stress and fretting load $\left(Q / B\right.$ fixed). The threshold loading conditions separating infinite live $\left(10^{6}\right.$ cycles) from failure was identified. Arrested cracks were found in some of the unbroken specimens.

A novel approach to the prediction of fatigue based on the use of a $T$-stress based criterion was described. A method to identify the parameters $\delta$ and $K_{I Y}$ of this model was presented. These parameters were nevertheless calibrated for this work based on data collected from the literature [5][9].

This generalized Von Mises yield criterion was applied to fretting fatigue prediction, and different new representations of the criterion were introduced. It was showed that if a vertical crack path was assumed, short crack propagation was not observed in any case under the trailing edge of the contact, while experimentally, the more severe case leads to the failure of the specimen. This vertical crack assumption was replaced and a path research algorithm developed to predict crack growth. This method based on a maximization of the criterion proved successful in capturing the effect of the stress gradient and was able to correctly estimate short crack arrest and also early growth direction.

On the other hand, one should observe that LEFM requires small scale yielding (SSY) conditions ahead of the crack tip since the stress intensity factor, which characterizes the stress field in such region and is the key factor within the LEFM framework, was obtained from an elastic formulation. When SSY conditions prevail, crack growth can be described in terms of Paris law. For short cracks various researchers have found an anomalous behavior when their growth is described in terms of $\Delta K$. For such small cracks, accelerations and retardations in crack speed have been observed for low values of $\Delta K$ in the $d a / d N$ vs $\Delta K$ diagram. Further, crack growth rates have been reported to be higher than the ones observed for long cracks in terms of the same $\Delta K$ and $\Delta K_{t h}$ is not a material constant but varies with crack size. In fretting fatigue, engineering approaches, based on LEFM concepts, have been proposed in order to establish a short crack arrest methodology. In these methods the growth of the crack can be described with the mode I SIF range or with an effective stress intensity range, which is a combination of the mode I and mode II SIFs [34, 37]. In those works the anomalous short crack behaviour has been captured by considering that the SIF range threshold is not a material constant but depends on crack size until a critical length (e.g., El Haddad's parameter). In the present model, it is not necessary to define a fictitious crack size do describe such anomalous behavior. The variation of the threshold for $\Delta K$ within the short crack regime can be captured by taking into account the influence of the T-stress. Moreover, the computation of the critical distortional elastic energy generates mix mode dependence implicitly. The description of the criterion based on the concept of a two parameter ( $K$ and $T$ ) allows the description of the stress/strain field in a region larger than the $\mathrm{K}$ dominated zone. This is essential to deal with the small crack problem where the $\mathrm{K}$ dominated zone is extremely reduced. Nevertheless, it should be kept in mind that, as the other K based short crack approaches available, the model proposed here has to be seen as an engineering solution as it is not clear that SSY are attended. However, the successful estimates of short crack arrest obtained here seems to show somehow that the model is capable to capture the underlying physics of the phenomenon.

For larger crack sizes, the application of the proposed methodology have shown a unexpected comportment. Indeed, when the crack reaches a size around $140 \mu m$, the crack path predicted turns 
to a direction out side the contact zone, which is not in accordance with the actual path, where crack directions are usually observed to be perpendicular to the axial main fatigue load direction (mode I dominant). Indeed, the maximum of the criterion is observed in a plane inclined at $45^{\circ}$, which reflects a mode II dominance.

This failure of the proposed model to estimate long crack propagation may come from the formulation the criterion itself, or/and from assumptions used to simplify the numerical modeling. It is well known that the threshold stress intensity factor depends of the loading ratio [14]. Indeed, when plasticity occurs, if the plastic zone is confined, residual stresses arise in the vicinity of the crack front. These constraints produce a shielding effect [32], which is superimposed on the applied load. This phenomenon, also called displacement of the elastic domain, is not included in the current formulation of the criterion. A enhanced version of the criterion would include the shift of the center of the elasticity domain $\mathbf{K}^{X}=\left(K_{I}^{X}, K_{I I}^{X}\right)$, so that Eq.7 could be re-written as Eq.12.

$$
f=\left(\frac{K_{I}-K_{I}^{X}}{K_{I Y}}\right)^{2}+\left(\frac{K_{I I}-K_{I I}^{X}}{K_{I I Y}}\right)^{2}+\left(\frac{T}{T_{Y}}\right)^{2}+f_{1} \frac{K_{I}-K_{I}^{X}}{K_{I Y}} \frac{T}{T_{Y}}-1=0
$$

This effect was studied by Fremy [33], and gave good results for long cracks, however its application to the short crack regime and a correction for the T-stress terms have not been tried yet. Since the load ratio changes at the crack tip depending on the crack growth orientation (Tab.4), it seems reasonable to expect that a enhanced estimate of crack path can be obtained by including the displacement of the elastic domain in the proposed model.

Another likely reason of the prediction failure for long crack is the modeling of the crack closure. In the current finite elements modeling, the fracture roughness is not considered; the crack is modeled as a number of straight planes with a Coulomb interaction between them. In this case, the tangential stress between fracture faces is proportional to the pressure between the crack faces and sliding may occur. However it is well known that crack roughness limits considerably the shear stress transmitted to the crack tip when crack closure happens. Hence, the real mode II stress intensity factor $K_{I I}$ (seen at the tip of the crack) may be considerably smaller than the one computed here. This drop of $K_{I I}$, which is proportional to the crack length, is sometimes used to explain the transition between the different stages of the crack growth. Indeed, crack initiation is generally mode II dominant, however after a certain length of the crack, the shear resistance of crack faces is such that propagation will be directed by the mode I. In fretting fatigue, the constant pressure of the pad tends to close the crack during a non-negligible period of the cycle, even for small positive values of the bulk fatigue load. The non consideration of the roughness induced crack closure may as well explains the unexpected propagation in mode II of long cracks in this proposition.

\section{Acknowledgement}

The authors would like to thank Snecma (Safran group) in France for their financial support and for fruitful discussions. Professor Araújo also would like to acknowledge the support of the National Council of Technological and Scientific Development from Brazil - CNPq under Contract 304648/2010-8. 


\section{References}

[1] T. Lindley, Fretting fatigue in engineering alloys, International Journal of Fatigue 19 (1997) 39-49.

[2] C. Ruiz, K. Chen, Life assessment of dovetail joints between blades and discs in aero-engines, Proc. Int. Conf. Fatigue (1986).

[3] G. Harish, T. N. Farris, Shell modeling of fretting in riveted lap joints, AIAA Journal 36 (1998) 1087-1093.

[4] E. Thieulot-Laure, S. Pommier, S. Fréchinet, A multiaxial fatigue failure criterion considering the effects of the defects, International Journal of Fatigue 29 (2007) 1996-2004.

[5] R. b. De Moura Pinho, S. Pommier, C. Mary, A. Longuet, F. Vogel, A novel methodology to predict the endurance domain for a material and its evolution using a generalized fracture mechanics framework, International Journal of Fatigue 42 (2012) 183-193.

[6] Carlos Navarro and Sergio Muñoz and Jaime Domínguez, On the use of multiaxial fatigue criteria for fretting fatigue life assessment, International Journal of Fatigue 30 (2008) 32-44.

[7] D. Nowell, D. Dini, D.A. Hills, Recent developments in the understanding of fretting fatigue, Engineering Fracture Mechanics 73 (2006) 207-222.

[8] S. Fouvry, Ph. Kapsa, L. Vincent, Multiaxial fatigue analysis of fretting contact taking into account the size effect, ASTM (2000) 167-182.

[9] J. Araújo, L. c. Susmel, D. Taylor, J. Ferro, E. Mamiya, On the use of the theory of critical distances and the modified whler curve method to estimate fretting fatigue strength of cylindrical contacts, International Journal of Fatigue 29 (2007) 95-107.

[10] H. Proudhon, S. Fouvry, G.R. Yantio, Determination and prediction of the fretting crack initiation: introduction of the $(\mathrm{P}, \mathrm{Q}, \mathrm{N})$ representation and definition of a variable process volume, International Journal of Fatigue 28 (2006) 707-713.

[11] Y.J. Xie, D.A. Hills, Crack initiation at contact surface, Theoretical and Applied Fracture Mechanics 40 (2003) 279-283.

[12] J. McEvily, M. Endo, S. Ishihara, The influence of biaxial stress on the fatigue behavior of defect-containing steels, in: Proc. of the $11^{\text {th }}$ ICF conference Torino (Italy), 2005.

[13] T. Delahay, Dveloppement d'une méthode probabiliste de calcul en fatigue multiaxiale prenant en compte la rpartition volumique des contraintes., Ph.D. thesis, Universit Bordeaux I, 2004.

[14] M. Moshier, T. Nicholas, B. Hillberry, Load history effects on fatigue crack growth threshold for ti6al4v and ti-17 titanium alloys, International Journal of Fatigue 23, Supplement 1 (2001) 253-258.

[15] D. Nowell, An analysis of fretting fatigue, Ph.D. thesis, Oxford University, 1988.

[16] L. Martins, L. Rossino, W. Bose Filho, J. Araújo, Detailed design of fretting fatigue apparatus and tests on 7050-t7451 al alloy, Tribology - Materials, Surfaces and Interfaces 2 (2008) 39-49.

[17] D.A. Hills, D. Nowell, Mechanics of Fretting Fatigue, Kluwer academic publishers (1993).

[18] J. Araújo, D. Nowell, Analysis of pad size effects in fretting fatigue using short crack arrest methodologies, International Journal of Fatigue 21 (1999) 947-956.

[19] M. L. Williams, On the stress distribution at the base of a stationary crack, Journal of Applied Mechanics 24 (1957) 109-114.

[20] S.G. Larsson, A.J. Carlsson, Influence of non-singular stress terms and specimen geometry on small-scale yielding at crack tips in elastic-plastic materials, Journal of the Mechanics and Physics of Solids 21-4 (1973) 263-277.

[21] J. Tong, T-stress and its implications for crack growth, Engineering Fracture Mechanics 69-12 (2002) $1325-1337$.

[22] X. Wang, Elastic t-stress solutions for penny-shaped cracks under tension and bending, Engineering Fracture Mechanics 71 (2004) 2283-2298.

[23] H. Schütte, K. Molla-Abbasi, On the full set of elastic t-stress terms of internal circular cracks under mixed-mode loading conditions, Engineering Fracture Mechanics 74 (2007) 2770-2787.

[24] S. Pommier, P. Lopez-Crespo, P. Decreuse, A multi-scale approach to condense the cyclic elastic-plastic behaviour of the crack tip region into an extended constitutive model, Fatigue and Fracture of Engineering Materials and Structures 32 (2009) 899-915.

[25] P. Golden, A. G. Jr., Fracture mechanics based fretting fatigue life predictions in ti-6al-4v, Engineering Fracture Mechanics 71 (2004) 2229-2243.

[26] J. Peters, B. Boyce, X. Chen, J. McNaney, J. Hutchinson, R. Ritchie, On the application of the kitagawatakahashi diagram to foreign-object damage and high-cycle fatigue, Engineering Fracture Mechanics 69 (2002) $1425-1446$.

[27] A. Hutson, T. Nicholas, R. John, Fretting fatigue crack analysis in ti-6al-4v, International Journal of Fatigue 27 (2005) 1582-1589. 
[28] S. Pommier, J. Bellecave, J. Araújo, J. Meriaux, R. De Moura Pinho, Short crack growth in stress gradient from fretting-fatigue loadings, SF2M (2012).

[29] F. Brugier, S. Pommier, R. Moura Pinho, C. Mary, D. Soria, A novel approach to predict the growth rate of short cracks under multiaxial loadings, in: International Conference on Multiaxial Fatigue \& Fracture, 2013.

[30] Abaqus Analysis User's Manual, contour integral evaluation, section 11.4.2 ed., 2011.

[31] S. b. Norberg, M. Olsson, A fast, versatile fatigue post-processor and criteria evaluation, International Journal of Fatigue 27 (2005) 1335-1341.

[32] J. Rice, Limitations to the small scale yielding approximation for crack tip plasticity, Journal of the Mechanics and Physics of Solids 22 (1974) 17-26.

[33] F. Fremy, Fissuration par fatigue en mode mixte I+II+III non proportionnel dans l'acier 316L, Ph.D. thesis, LMT Cachan, 2012.

[34] S. Fouvry, K. Kubiak, D. Nowell, D.A. Hills, Prediction of fretting crack propagation based on a short crack methodology, Engineering Fracture Mechanics 75 (2008) 1605-1622.

[35] D. Dini, D. Nowell, I.N. Dyson, The use of notch and short crack approaches to fretting fatigue threshold prediction: Theory and experimental validation, Tribology International 39 (2006) 1158-1165.

[36] D. Nowell, D.A. Hills, J.J. O Connor, On the Mechanics of Fretting Fatigue., Springer (1988).

[37] D.A. Hills, Inclined cracks in fretting fatigue, Engineering Fracture Mechanics 52 (1995) 71-82.

[38] D. Nowell, D.A. Hills, Open cracks at or near free edges., J Strain Anal 22(3) (1987) 177-186.

[39] D.A. Hills, P.A. Kelly, D.N. Dai, A. Korsunsky, Solutions of crack problems: the distributed dislocation technique, Kluwer academic publishers (1996). 